\title{
MARKETING MIX DAN KARAKTERISTIK KONSUMEN TERHADAP KEPUTUSAN PEMBELIAN DAN KEPUASAN PELANGGAN PADA SALON MUSLIMAH DI KOTA BOGOR
}

\section{MARKETING MIX AND CONSUMER CHARACTERISTICS ON PURCHASING DECISIONS AND CUSTOMER SATISFACTION IN MUSLIMAH SALONS IN BOGOR CITY}

\author{
A.E. Sagita1a; M. Najib²; M. Yasid³ \\ 1aProgram Bisnis Manajemen Syariah Pascasarjana Ekonomi Islam Insitut Tazkia, Jl. Ir. \\ H. Djuanda No.78,Sentul City Bogor 16810, e-mail: ajeng1312@gmail.com \\ ${ }^{2}$ Departemen Manajemen, Institut Pertanian Bogor, \\ ${ }^{3}$ Departement Multipascasarjana Ekonomi Islam Institut Tazkia, Jl. Ir. H. Djuanda No. \\ 78, Sentul City Bogor 16810
}

\begin{abstract}
ABSTRAK
Pergeseran gaya hidup wanita muslim yang lebih tertarik melakukan perawatan tubuhnya pada salon, maka hadirlah salon muslimah yang bisa memenuhi kebutuhan, perawatan, kebersihan dan kecantikan wanita muslim dengan tetap memegang teguh aturan dan prinsip syariah. Penelitian ini bertujuan untuk mengetahui pengaruh bauran pemasaran dalam keputusan pembelian menganalisis pengaruh karakteristik konsumen terhadap keputusan pembelian dan menentukan tingkat kepuasan pelanggan setelah menggunakan layanan di Muslimah Salon. Penelitian ini menggunakan pendekatan kuantitatif yang menekankan teori pengujian melalui pengukuran variabel penelitian menggunakan statistik. Metode penelitian yang digunakan adalah Path Analysis, yang merupakan teknik pengembangan regresi linier berganda yang digunakan untuk menguji jumlah kontribusi yang ditangani oleh koefisien jalur pada setiap diagram jalur hubungan kausal antara variabel X1, X2 ke Y dan Z. Hasil penelitiannya menunjukkan bahwa bauran pemasaran dan karakteristik konsumen secara langsung mempengaruhi keputusan pembelian, keputusan pembelian sebesar 0,708 atau 70,8\%. Sedangkan bauran pemasaran, karakteristik konsumen dan keputusan pembelian secara langsung mempengaruhi kepuasan pelanggan sebesar 0,212 atau 78\% berdasarkan penelitian ini dapat disimpulkan bahwa bauran pemasaran, karakteristik pelanggan dapat mempengaruhi keputusan pembelian dan kepuasan pelanggan.
\end{abstract}

Kata Kunci: Marketing mix, Karakteristik Konsumen, Keputusan Pembelian, Kepuasan Pelanggan 


\begin{abstract}
Lifestyle of muslim women in Bogor who are more interested in body care at the salon, then there is the muslimah salon which can fulfill the needs for care, hygiene and beauty of muslimah women while still adhering to the rules and principles of sharia. This research aims to determine the effect of marketing mix in purchasing decisions analyze the influence of consumer characteristics on purchasing decisions and determine the level of customer satisfaction after using the services in muslimah salon. This study uses a quantitative approach that emphasizes testing theory through measurement of research variables using statistics. The research method used is Path Analysis, which is a development technique of multiple linear regression used to test the amount of contribution addressed by the path coefficient on each path diagram of the causal relationship between variables $\mathrm{X} 1, \mathrm{X} 2$ to $\mathrm{Y}$ and $\mathrm{Z}$. The results of his research show that marketing mix and consumer characteristics directly influence purchasing decisions, purchasing decisions of 0,708 or $70,8 \%$. While the marketing mix, consumer characteristics and purchasing decisions directly affect customer satisfaction by 0,212 or $78 \%$ based on the research it can be concluded that the marketing mix, costumer characteristic can influence purchasing decision and costumer satisfaction.
\end{abstract}

Keywords: Marketing Mix, Consumer Characteristics, Purchasing Decisions, Customer Satisfaction

$\overline{\text { Sagita, A.E., dkk. 2020. Marketing Mix dan Karakteristik Konsumen Terhadap Keputusan }}$ Pembelian dan Kepuasan Pelanggan Pada Salon Muslimah Di Kota Bogor. Jurnal Syarikah 6 (1): 47 - 57.

\section{PENDAHULUAN}

Kegiatan yang padat membuat orang memerlukan tempat untuk merelaksasikan tubuh dan pikiran dengan merawat tubuhnya, terutama bagi kaum wanita. Memanjakan, merawat dan mempercantik diri merupakan kebutuhan setiap wanita. Namun, seiring dengan perkembangan zaman dan adanya pengaruh dari budaya luar yang masuk maka kegiatan merawat tubuh dan mempercantik diri pun bergeser menjadi suatu gaya hidup (lifestyle) masyarakat (Miranti, 2011) .Pengukuran gaya hidup dapat dilakukan dengan aktivitas atau sikap, ketertarikan atau minat dan pendapat konsumen terhadap suatu aktivitas. Dengan memanjakan, merawat, dan mempercantik diri merupakan kegiatan menyenangkan yang sudah menjadi gaya hidup bagi sebagian besar kaum wanita saat ini.

Salah satu tempat yang menunjang kegiatan tersebut adalah salon. Salon merupakan salah satu bentuk usaha yang bergerak di bidang jasa yang bertujuan untuk memperbagus dan mempercantik fisik seseorang. Perkembangan bisnis salon diikuti dengan pertumbuhan jumlah 
penduduk perempuan di kota Bogor. Menurut badan statistika penduduk perempuan dikota Bogor pada tahun 2018 mencapai 524.399 juta jiwa. Hal ini diikuti pula dengan perkembangan usaha salon kecantikan yang semakin menjamur, hal ini menunjukkan bahwa salon sudah menjadi gaya hidup bagi sebagian kaum wanita untuk mempercantik diri. Salon pada umumnya terbuka bagi kaum pria dan wanita, namun seiring berkembangnya kebutuhan dari berbagai kalangan konsumen khususnya wanita muslimah yang juga ingin merawat dan mempercantik diri membutuhkan ruang khusus yang nyaman bagi mereka untuk pergi ke salon. Beriku ini perbedaan salon Konvensional dan Salon Muslimah:

Tabel 1. Perbedaan Salon Konvensional dan Salon Muslimah

\begin{tabular}{|c|c|c|}
\hline Jenis & $\begin{array}{c}\text { Salon } \\
\text { Wanita } \\
\end{array}$ & $\begin{array}{c}\text { Salon } \\
\text { Muslimah }\end{array}$ \\
\hline Pengunjung & $\begin{array}{l}\text { Semua } \\
\text { Wanita } \\
\end{array}$ & $\begin{array}{l}\text { Khusus } \\
\text { Muslim saja } \\
\end{array}$ \\
\hline $\begin{array}{l}\text { Jenis } \\
\text { Perawatan } \\
\text { (Treatment } \\
\text { ) }\end{array}$ & $\begin{array}{l}\text { Dilakukan } \\
\text { mengikuti } \\
\text { semua trend } \\
\text { mode }\end{array}$ & $\begin{array}{l}\text { Yang } \\
\text { diperbolehk } \\
\text { an secara } \\
\text { syari }\end{array}$ \\
\hline Karyawan & $\begin{array}{l}\text { Muslim dan } \\
\text { Non Muslim }\end{array}$ & $\begin{array}{l}\text { Muslim yang } \\
\text { berakhlah } \\
\text { baik dan } \\
\text { mengerti } \\
\text { syariat } \\
\text { agama }\end{array}$ \\
\hline Suasana & $\begin{array}{l}\text { Moderen dan } \\
\text { Nyaman }\end{array}$ & $\begin{array}{l}\text { Nyaman, } \\
\text { Lebih Islami } \\
\text { dengan } \\
\text { lantunan } \\
\text { lagu islami } \\
\text { dan fasilitas } \\
\text { sesuai } \\
\text { syariat islam }\end{array}$ \\
\hline $\begin{array}{l}\text { Bahan yang } \\
\text { digunakan }\end{array}$ & $\begin{array}{l}\text { Tidak perlu } \\
\text { halal }\end{array}$ & $\begin{array}{ll}\text { Bahan } & \text { yang } \\
\text { alami } & \text { atau } \\
\text { Halal } & \end{array}$ \\
\hline
\end{tabular}

Salon juga harus memperhatikan penggunaan marketingmix (7P) yang tepat pada seperti produk (product) yang berkualitas, harga (price) yang bersaing, tempat (place) yang strategis, promosi (promotion) yang tepat, proses (process) perawatan yang tepat, orang (people) yang professional dan bukti fisik (physical evident) yang sesuai agar salon dapat memberikan kepuasan pelanggan yang maksimal sesuai harapan konsumen.

\section{MATERI DAN METODE}

\section{Marketing Mix (Bauran Pemasaran)}

Dalam mengelola salon muslimah diperlukan starategi yang baik dan tepat sasaran bagi konsumen, hal ini tidak lepas dari strategi pemasaran yang ampuh untuk memasarkan produkproduk yang dihasilkan, strategi tersebut adalah marketing mix atau dikenal dengan bauran pemasaran. Marketing mix atau bauran pemasaran adalah kombinasi dari empat variabel yang merupakan inti dari sistem pemasaran yang dapat dikendalikan oleh perusahaan.

Pemasaran memiliki fungsi inti yang terdiri dari :

1. Bauran pemasaran yang berupa unsur unsur atau elemen elemen internal penting yang membentuk program pemasaran sebuah organisasi.

2. Kekuatan pasar berupa peluang dan ancaman external dimana operasi pemasaran sebuah organisasi berinteraksi.

3. Proses penyelarasan yaitu proses strategi dan managerial untuk memastikan bahwa bauran pemasaran dan kebijakan internal baik bagi kekuatan pasar. 
Bauran pemasaran menurut Kotler dan Amstrong (2014) adalah "seperangkat alat pemasaran terkontrol yang dipadukan oleh perusahaan untuk menghasilkan respon yang diinginkan pasar sasaran."

\section{Karakteristik Konsumen}

Menurut Sangadji

Karakteristik konsumen dipengaruhi oleh beberapa faktor yaitu

a. Demografik, dimana konsumen dikelompokan berdasarkan kelas social, etnis, usia, pendidikan, penghasilan, agama, dll

b. Prefensi pembelian produk, dimana konsumen dikelompokan berdasarkan prefensi pembeliana seperti keluarga, teman, kelompok referensi dan lainnya.

c. Prefensi manfaat produk bagi konsumen yaitu manfaat inti dari produk dan atribut produk

d. Gaya hidup konsumen (kepribadian) yaitu dikelompokan menjadi gaya hidup orang kota, modern atau kembali kealam.

\section{Keputusan Pembelian}

Keputusan pembelian yang terus dilakukan secara berulang-ulang akan menjadi pembelian kembali (Purchase Intentions). Purchase Intentions are defined as "the individual's judgment about buying again a designated service from the same company, talking into account his or her current situation and likely circumstances"(Hellier, 2003). Adapun proses keputusan pembelian adalah sebagai berikut:

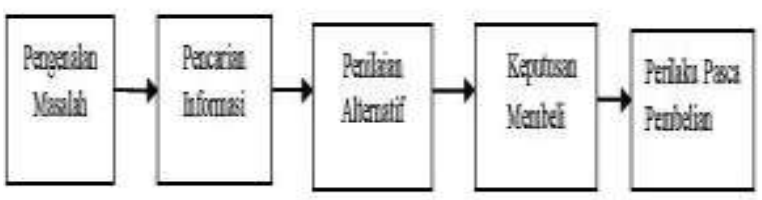

Sumber :Kotler dan Keller (2016)

Gambar 1. Proses Pengambilan

Keputusan

\section{Kepuasan Pelanggan}

Definisi kepuasan pelanggan menurut Kotler (2014:150) ialah "Perasaan senang atau kecewa yang muncul setelah membandingkan kinerja (hasil) produk yang dipikirkan terhadap kinerja (atau hasil) yang diharapkan" Dari definisi tersebut dapat dikatakan apabila kinerja produk tidak sesuai dengan harapan tamu salon dan bila harapan yang ditetapkan terlalu rendah, maka tamu salon tersebut akan merasa tidak puas dan berujung kecewa, jika kinerja sesuai dengan harapan maka tamu salon akan merasa puas, namun apabila kinerja produk melampaui harapan, maka tamu salon akan merasa gembira dan sangat puas. Dalam industri jasa, kepuasan pelanggan diukur dengan tingkat kepuasan pelanggan berdasarkan keseluruhan pengalaman dengan perusahaan. Dengan kata lain, kepuasan tamu salon dapat diukur dengan tingkatannya berdasarkan keseluruhan pengalaman yang dirasakan para tamu selama melakukan perawatan di salon.

\section{Metodologi Penelitian}

Dalam penelitian ini dapat dibuat suatu kerangka pemikiran yang dapat menjadi landasan penulisan ini yang pada akhirnya dapat diketahui variable mana yang paling dominan mempengaruhi keputusan pembelian serta implikasinya terhadap kepuasan pelanggan. Kerangka pemikiran ini dapat digambarkan sebagai berikut: 


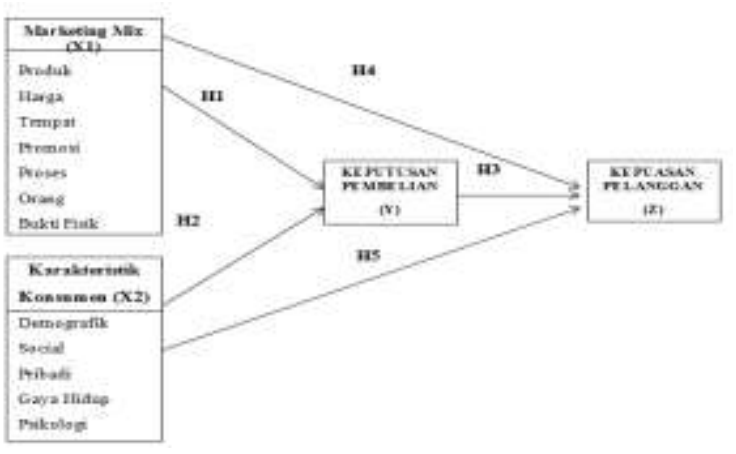

Gambar 2. kerangka pemikiran

Penelitian ini menggunakan pendekatan kuantitatif yaitu jenis penelitian yang menekankan pada pengujian teori teori melalui pengukuran variable penelitian dengan angka dan memerlukan analisis data dengan prosedur statistik. Dalam penelitian ini menggunakan Analisis Jalur (Path Analysis), dimana suatu teknik pengembangan dari regresi linier ganda. Teknik ini digunakan untuk menguji besarnya sumbangan (kontribusi) yang ditunjukkan oleh koefisien jalur pada setiap diagram jalur dari hubungan kausal antar variabel $\mathrm{X}_{1} \mathrm{X}_{2}$ dan $\mathrm{X}_{3}$ terhadap $\mathrm{Y}$ serta dampaknya terhadap $\mathrm{Z}$.

Adapun lokasi penelitian yang digunakan dalam penelitian ini adalah Salon Muslimah House of Aisyah yang berada di jalan Hateup no.20 Bantar Jati Bogor, House of Khadijah di Ruko Laladon dan Amalia Salon Muslimah di Yasmin Bogor yang merupakan beberapa perawatan dan kencantikan wajah dan tubuh khusus Muslimah.

Pengunjung salon muslimah di Bogor tiap harinya mengalami perubahan yang disebabkan penambahan atau penurunan jumlah konsumen, oleh karena itu jumlah populasi dalam penelitian ini diasumsikan tidak diketahui. Sehingga teknik pengambilan sampel yang digunakan masuk ke kategori non-probability sampling dimana teknik pengambilan sampel nonprobability sampling yang dipilih adalah teknik accidental/incidental yaitu menggunakan individu-individu yang telah memenuhi karakteristik penelitian dan kebetulan dijumpai oleh peneliti. Alasannya, meningkatkan kepraktisan (mudah dilakukan) dan efisiensi penelitian (menghemat waktu, biaya, dan tenaga penelitian). Untuk menghitung jumlah sampel yang dibutuhkan peneliti menggunakan rumus Malhotra. Menurut Malhotra dalam analisis faktor ukuran sampel yang diambil dapat ditentukan dengan cara mengalikan jumlah indikator dengan 5, atau $5 \mathrm{x}$ jumlah variable/indikator. Dengan demikian $5 \mathrm{x}$ 49 variabel $=245$ responden. Dalam penelitian ini dilakukan pembulatan keatas sehingga jumlah sampel yang digunakan 250 Konsumen pada Salon Muslimah yang terdapat di Kota Bogor.

\section{HASIL DAN PEMBAHASAN}

\section{Karakteristik Responden}

Penelitian ini mengambil sample di 3 Salon Muslimah yang berada di Kota bogor, Berikut ini adalah hasil perolehan sampling terhadap konsumen Salon Muslimah di Kota Bogor :

Tabel 2. Perolehan Sampling Penelitian

\begin{tabular}{cccc}
\hline No & \multicolumn{1}{c}{ Nama } & $\begin{array}{c}\text { Kuisioner } \\
\text { Yang } \\
\text { dikirim }\end{array}$ & $\begin{array}{c}\text { Kuisioner } \\
\text { yang } \\
\text { dikembalikan }\end{array}$ \\
\hline 1 & $\begin{array}{l}\text { House Of } \\
\text { Aisyah }\end{array}$ & 100 & 88 \\
2 & $\begin{array}{l}\text { House of } \\
\text { Khadijah }\end{array}$ & 100 & 93 \\
3 & $\begin{array}{l}\text { Amalia } \\
\text { Salon }\end{array}$ & 70 & 69 \\
\hline & JUMLAH & 270 & 250 \\
\hline
\end{tabular}


Sumber : Data Primer

Karakteristik responden yang diteliti adalah berupa data diri seperti nama, usia, status, pekerjaan, suku bangsa dan status pelanggan . Adapun karakteristik respondennya sebagai berikut :

1. Usia

Hasil penelitian menujukan bahwa dari 250 responden yang lebih besar dari 20 tahun yaitu sebesar 65,2\% dengan 163 responden, sedangkan yang lebih kecil dari 20 tahun yaitu sebesar $34,8 \%$ dengan 87 responden.

2. Status

Bahwa dari 250 responden yang lebih banyak adalah berstatus menikah yaitu sebesar 69,6\% dengan 174 responden, sedangkan yang belum menikah yaitu sebesar 30,4\% dengan 76 responden.

3. Pekerjaan

Berdasarkan hasil 250 responden yang lebih banyak adalah Pegawai swasta yaitu sebesar 28,8\% dengan 72 responden, wirausaha sebesar responden $21 \%$ dengan 52 responden, Pelajar/mahasiswi sebesar 17,6\% dengan 44 responden, TNI/POLRI sebesar 12,4\% dengan 31 responden, Guru/Dosen sebesar 8,4 \% dengan 21 responden. Dengan demikian data responden berdasarkan Pekerjaan menunjukan HN yang lebih banyak pada pekerjaan adalah Pegawai Swasta.

4. Suku

Dari 250 responden yang lebih banyak adalah suku Sunda yaitu sebesar $50,8 \%$ dengan responden 127 , suku Jawa 26,8\% dengan 67 responden, suku Betawi $17,2 \%$ dengan 43 responden, suku Madura 3,6\% dengan 9 responden dan lainnya $1,6 \%$ terdiri dari suku Batak dengan 4 responden.

5. Status Pelanggan

Berdasarkan hasil dari 250 responden yang lebih banyak adalah Pemegang Member yaitu sebesar 66,8\% dengan responden 167, dan Non-Member yaitu sebesar 33,2\% dengan jumlah responden 83 sehingga yang menjadi kategori paling dominan adalah pelanggan Member Salon di kota Bogor.

Pernyataan mengenai marketing mix terungkap melalui jawaban responden terhadap pertanyaan pertanyaan yang diajukan pada kuesioner. Marketing mix dinyatakan menggunakan $\quad 7 \quad \mathrm{P}$ yang dioperasionalkan melalui 38 butir pertanyaan. Berikut ini hasil kategori rata rata skor tanggapan responden terhadap setiap dimensi pada variable marketing mix.

Tabel 3. Rekapitulasi Mean Skor Jawaban

Responden Mengenai Marketing mix, Karakteristik Konsumen, Keputusan

Pembelian dan Kepuasan pelanggan

\begin{tabular}{|l|l|l|}
\hline $\begin{array}{c}\text { Dimensi Grand } \\
\text { Mean }\end{array}$ & \multicolumn{1}{|c|}{$\begin{array}{c}\text { Mean } \\
\text { Skor }\end{array}$} & Kategori \\
\hline Marketingmix & 4,45 & Tinggi \\
\hline $\begin{array}{l}\text { Karakteristik } \\
\text { Konsumen }\end{array}$ & 4,6 & Tinggi \\
\hline $\begin{array}{l}\text { Keputusan } \\
\text { Pembelian }\end{array}$ & 4,51 & Tinggi \\
\hline $\begin{array}{l}\text { Kepuasan } \\
\text { Pelanggan }\end{array}$ & 4,6 & Tinggi \\
\hline Rata Rata & 4,54 & Tinggi \\
\hline
\end{tabular}

Dengan demikian dapat disimpulkan bahwa responden menyatakan bahwa Marketing Mix, Karakteristik Konsumen, Keputusan Pembelian, Kepuasan Pelanggan pada sebagian besar Salon Muslimah yang 
diteliti adalah memiliki kompetensi yang tinggi.

\section{Hasil Uji Sub Struktur 1}

Pada hasil uji Sub Struktur Jalur 1 didapatkan hubungan kausal empiris sebagai berikut :

$Y=0,134 X 1+0,749 X 2+0,271 \Sigma 1$

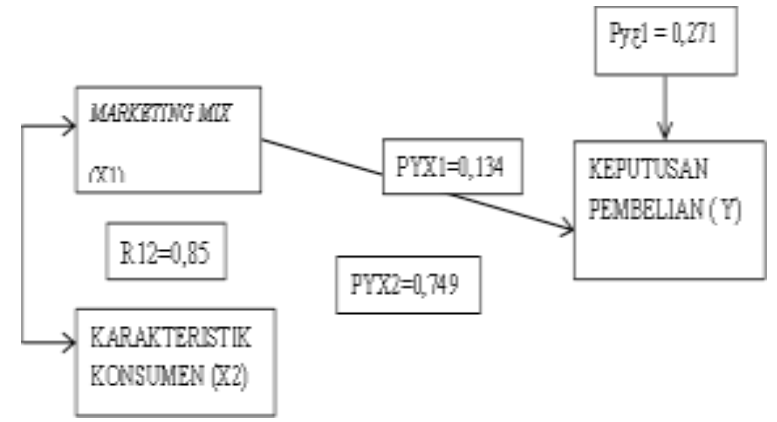

Gambar 3. Hubungan Kausal Empiris

Sub Struktural 1

Sehingga terbukti bahwa pertanyaan marketing mix dan karakteristik konsumen berpengaruh secara simultan dan signifikan terhadap keputusan pembelian. Koefesien Jalur, Kontribusi Langsung, Tidak Langsung, Marketing mix (XI). Adapun karakteristik konsumen (X2), terhadap keputusan pembelian (Y) sebagai berikut :

Tabel 4. Tabel Koefesien Jalur, Kontribusi Langsung, Tidak Langsung, Marketing mix

(XI), Karakteristik Konsumen (X2), terhadap Keputusan pembelian (Y)

\begin{tabular}{|l|l|l|l|l|l|}
\hline \multirow{2}{*}{$\begin{array}{l}\text { Varia } \\
\text { bel }\end{array}$} & $\begin{array}{l}\text { Koef.J } \\
\text { alur }\end{array}$ & $\begin{array}{l}\text { Langs } \\
\text { ung }\end{array}$ & $\begin{array}{l}\text { Tidak } \\
\text { Langs } \\
\text { ung }\end{array}$ & $\begin{array}{l}\text { Tot } \\
\text { al }\end{array}$ & $\begin{array}{l}\text { busi } \\
\text { Bersa } \\
\text { ma }\end{array}$ \\
\hline X1 & 0,134 & 0,134 & & $\begin{array}{l}86, \\
6 \%\end{array}$ & \\
\hline X2 & 0,749 & 0,749 & & $\begin{array}{l}25, \\
1 \%\end{array}$ & \\
\hline$\Sigma 1$ & 0,271 & 0,271 & & $\begin{array}{l}72, \\
9 \%\end{array}$ & \\
\hline $\begin{array}{l}\text { X1 } \\
\text { dan } \\
\text { X2 }\end{array}$ & & & & & $0,708=$ \\
\hline
\end{tabular}

Sumber: Data Primer yang diolah
Berdasarkan hasil perhitungan analisis jalur sub struktural 1 tersebut maka memberikan informasi secara objektif sebagai berikut :

1. Berdasarkan kontribusi marketing mix (X1) yang secara langsung dan signifikan mempengaruhi keputusan pembelian (Y) adalah $0,134^{2}=0,0179$

2. Besar kontribusi karakteristik konsumen (X2) yang secara langsung dan signifikan mempengaruhi keputusan pembelian (Y) adalah $0,749^{2}=0,561$

Besarnya kontribusi marketing mix (X1) dan karakteristik konsumen secara simultan yang langsung dan signifikan mempengaruhi keputusan pembelian (Y) adalah 0,708 atau 70,8\%. Sisanya sebesar $29,2 \%$ dipengaruhi oleh faktor faktor lain yang tidak dijelaskan dalam penelitian.

\section{Hasil Uji Sub Struktural 2}

Pada Hasil Uji Sub Struktural 2 didapatkan hubunngan kausal empiris sebagai berikut :

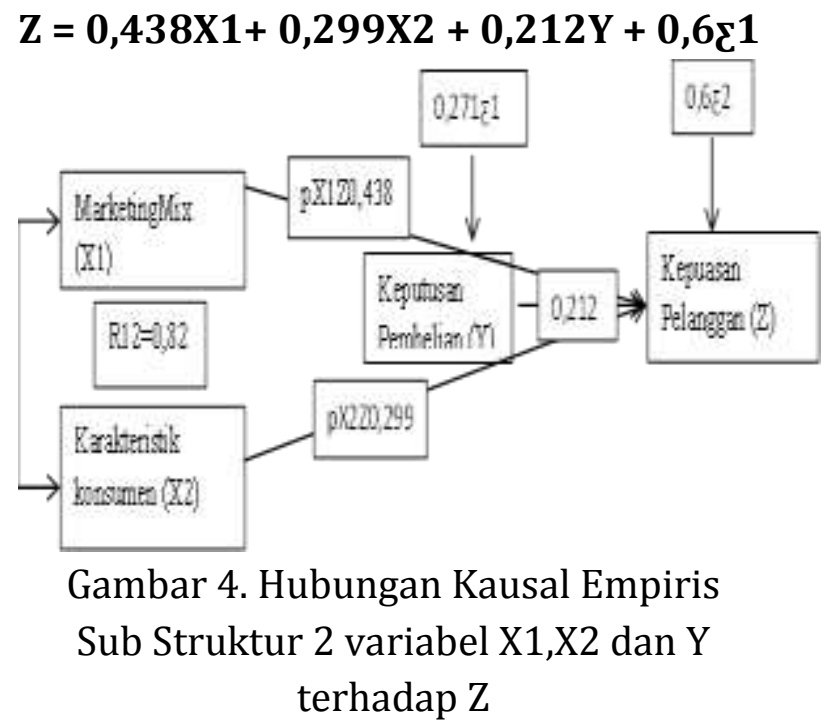

Berdasarkan anova diperoleh nilai $\mathrm{F}$ sebesar 331,787 dengan nilai probabilitas (sig) $=0,000$, karena nilai sig 0,000 0,05 maka keputusannya adalah Ho ditolak dan Ha diterima. Sehingga terbukti bahwa pertanyaan marketing mix, karakteristik 
konsumen, keputusan pelanggan berpengaruh secara simultan dan signifikan terhadap kepuasan pelanggan.

Tabel 5. Koefesien Jalur, Kontribusi Langsung, Tidak Langsung, Marketing mix

(XI), Karakteristik Konsumen (X2), Keputusan pembelian (Y) terhadap Kepuasan Pelanggan (Z)

\begin{tabular}{|c|c|c|c|c|c|}
\hline \multirow{2}{*}{$\begin{array}{c}\text { Varia } \\
\text { bel }\end{array}$} & \multirow{2}{*}{$\begin{array}{c}\text { Koef.J } \\
\text { alur }\end{array}$} & $\begin{array}{c}\text { Langs } \\
\text { ung }\end{array}$ & $\begin{array}{c}\text { Tidak } \\
\text { Berpeng } \\
\text { aruh }\end{array}$ & $\begin{array}{c}\text { Tot } \\
\text { al }\end{array}$ & $\begin{array}{c}\text { Kontri } \\
\text { busi } \\
\text { Bersa } \\
\text { ma }\end{array}$ \\
\hline X1 & 0,435 & 0,435 & & $\begin{array}{c}56, \\
5 \%\end{array}$ & \\
\hline X2 & 0,299 & 0,299 & & $\begin{array}{c}70, \\
1 \%\end{array}$ & \\
\hline$Y$ & 0,212 & 0,212 & & $\begin{array}{c}78, \\
8 \%\end{array}$ & \\
\hline$\Sigma 1$ & 0,271 & 0,271 & & $\begin{array}{c}72, \\
9 \%\end{array}$ & \\
\hline$\Sigma 2$ & 0,6 & 0,6 & & 60 & \\
\hline $\begin{array}{c}\text { X1 } \\
\text { X2 } \\
\text { Dan } \\
Y\end{array}$ & & & & & 0,80 \\
\hline
\end{tabular}

Sumber: Data primer yang diolah

Berdasarkan hasil perhitungan analisis jalur sub struktural 2 tersebut maka memberikan informasi secara objektif sebagai berikut :

(1) Berdasarkanm kontribusi marketing mix (X1) yang secara langsung dan signifikan mempengaruhi kepuasan pelanggan $(\mathrm{Z})$ adalah $=0,435$ atau $56,5 \%$

(2) Besar kontribusi karakteristik konsumen (X2) yang secara langsung dan signifikan mempengaruhi kepuasan pelanggan $(\mathrm{Z})$ adalah = 0,299 atau $70,1 \%$

(3) Besarnya kontribusi keputusan pembelian (Y) secara simultan yang langsung dan signifikan mempengaruhi kepuasan pelanggan (Z) adalah 0,212 atau 78,8\%.
(4) Sisanya sebesar 20\% dipengaruhi oleh faktor lain yang tidak dijelaskan dalam penelitian.

\section{KESIMPULAN DAN IMPLIKASI}

Dari hasil penelitian serta pembahasan yang telah dilakukan pada bab sebelumnya, maka kesimpulan yang dapat diambil dari pengaruh marketing mix dan karakteristik konsumen terhadap keputusan pembelian dan kepuasan pelanggan pada salon muslimah di kota Bogor .

Marketing mix memiliki pengaruh positip dan signifikan terhadap keputusan pembelian artinya marketing mix pengaruh terhadap pengambilan keputusan konsumen dari segi pemilihan produk yang digunakan, harga yang diberikan, tempat yang strategis, promosi yang tepat sasaran, keahlian karyawan dalam melayani konsumen, fasilitas yang diberikan akan sangat berpengaruh. Semakin baik kualitas dari marketing mix pada salon muslimah maka semakin tinggi tingkat keputusan yang diambil oleh pelanggan. Begitu juga dengan karakteristik konsumen memiliki pengaruh paling dominan dibandingkan marketing mix (X1) sebesar 0,749 dibandingkan marketing mix sebesar 0,134 dimana karakteristik konsumen ini dipegaruhi oleh demografik, social, ekonomi, psikologi dan gaya hidup terhadap keputusan pembelian konsumen artinya konsumen yang memilih salon muslimah hampir mendominasi memiliki karakteristik muslimah yang menginginkan keindahan dan kecantikan yang sesuai dengan aturan islam.

Kondisi salon muslimah di kota Bogor dirasakan masih sedikit 
dibandingkan jumlah permintaan konsumen, sebenarnya bisnis salon muslimah masih sangat membuka peluang yang cukup besar bagi bisnis di kota Bogor Sehingga dengan penelitian ini kita bisa belajar, mengamati dan melihat kebutuhan konsumen khususnya wanita muslimah untuk merawat diri dan menjaga kesehatan tubuhnya. Dengan segmentasi konsumen yang sangat terbatas menjadikan salon muslimah harus lebih innovative terhadap perkembangan produk halal dan perawatan yang lebih modern. Berkembangnya teknologi kecantikan yang halal dapat dijadikan daya tarik terhadap konsumen muslim untuk ikut merasakan manfaatnya tanpa harus ragu akan kehalalan. Dengan adanya pemilihan segmentasi pasar yang tepat yaitu khusus wanita muslimah yang menjalankan, mengerti dan taat kepada aturan agama menjadi salah satu targeting pasar salon muslmimah di kota Bogor. Hal ini dapat dijadikan acuan bagi perusahaan untuk menentukan strategi pemasaran yang lebih mengarah dalam menyusun marketing mix yang tepat.

\section{DAFTAR PUSTAKA}

Ali, Hasan. 2013. Marketing dan Kasus kasus pilihan. Yogyakarta CAPS (Center for Academic Publishing Service)

Anita 2012, Serba muslimah. Dikutip 10 April 2019 dari serba muslimah Buku

:http://serbamuslimah.com/perbed aan-salon-yang-biasanya-dengansalon-uslimah/
BPS Badan Pusat Statistik. 2018. Produk Domestik Regional Bruto ProvinsiProvinsi di Indonesia Menurut Jumlah penduduk 2017-2018. Katalog BPS930 2001.ISSN.01264796.Jakarta (ID). Badan Pusat Statistik.

Christopher Lovelock, Jochen Wirtz dan Jacky Mussry. 2010. Pemasaran Jasa, terj. Dian Wulandari dan Devri Barnadi Putera, Erlangga, Jakarta

Etta M. Sangaji dan Sopiah. 2013. Perilaku Konsumen, Yogyakarta: Andi Publisher.

Fajar Laksana. 2012. Manajemen Pemasaran, Graha Ilmu. Yogyakarta

Fandy Tjiptono, 2014. Pemasaran Jasa. Edisi Pertama. Andi,. Yogyakarta

Haghsenas, et all. 2013. Review Costumer Behaviour And Factor Affecting On 9Purchasing Decisions, Singapore journal of Business Economics and Management Studies Vol.1 No.10 Hal. 17-24

Huda Nurul, Handi Risza idris, Mustafa Edwin Nasution dan Ranti Wiliasih.2008. Ekonomi Makro Islam. Jakarta: Prenadamedia group Hurriyati Ratih, M. Si., 2010, Bauran Pemasaran \& Loyalitas Konsumen, Alfabeta, Bandung

Japrianto dan Djati. 2011. Pengaruh Service Retail Marketing mix terhadap Kepuasan Belanja Tourism Shopper di Plaza Plaza Surabaya, Jurnal Mitra Ekonomi dan Manajemen bisnis Vol.2 No.1 Hal 135-154

Jauhari Fadhill (2010) Kepribadian wanita muslim shalihah Dikutip 23 Pebuari 2010 dari Buku https://fadhlijauhari.wordpress.co 
$\underline{m} / /$ kepribadian-wanita-muslimahshalihah

Juliansyah Noor, 2012, Metodologi Penelitian, Kencana, Jakarta

Kara, Muslimin 2012. Pemikiran AlSyatibi Tentang Maslahah dan Implementasinya dalam pengembangan Ekonomi Syariah. Jurnal Ekonomi Syariah Vol.2 No.2

Kotler dan Amstrong,2012. Principle of Marketing. Jakarta: Erlangga.

Kotler, Philip and Gary Amstrong.(2016). Prinsip Prinsip Pemasaran. Edisi 13 Jilid 1. Jakarta : Erlangga.

Kotler, Philip. 2019. Manajemen Pemasaran 4.0: Analisis Perencanaan, Implementasi dan control.Jakarta: PT. Prehallindo.

Lupiyodi, Rambat. 2013. Manajemen Pemasaran Jasa berbasis kompetensi.(Edisi3) Jakarta: Salemba Empat

McKechnie, Sally, 2012. Costumer Buying Behaviour in Financial Service: An Overview. North California: University of North California.

Mowen,J.C.,dan Minor, M. 2012 Prilaku konsumen Jilid $1 . \quad$ Edisi kelima(terjemahan). Jakarta : Erlangga

Nasution. Mustafa Edwin. 2009 Pengenalan Ekslusif Ekonomi Islam. Jakarta:Prenada Media

Philip Kotler dan Gary Amstrong 2014, Prinsip Prinsip Pemasaran terj.Bob Sabran, Jakarta :Erlangga

Philip Kotler dan Gary Armstrong, 2009, Prinsip-Prinsip Pemasaran, terj. Damos Sihombing,Erlangga, Jakarta Philip Kotler dan Kevin Lane Keller, 2016, Manajemen Pemasaran, Edisi Kelima Belas Jilid I,terj. Bob Sabran, MM, Erlangga, Jakarta,
Pungnirund. (2013). The Influnce of Marketing Mix on Costumer Purchasing Behaviour at Chatuchak Plaza Market. Internasional journal of social, human and science and engineering vol:7 no.8 Hal 182-184

Rully Indrawan dan Poppy Yaniawati, 2014, Metode Penelitian Kuantitatif, Kualitatif, dan Campuran untuk Manajemen, Pembangunan, dan Pendidikan, PT Refika Aditama, Bandung,

Saleem, Sarfraz Raja 2014. The Impact of Service Quality on Customer Satisfafaction, Costumer loyalty and Brand Image: Evidence Journal from Hotel Industry of Pakistan Vol.3 No.11 Hal 18-25

Sani,Ahmad. Maharani,vivin. 2013. Metodelogi Penelitian Manajemen Sumber Daya Manusia. Malang: UINMaliki Press

Sefnedi 2013. Analisis Service Marketing Mix dan pengaruhnya terhadap Keputusan Pemilihan jasa pendidikan Program Pasca Sarjana, Jurnal Apresiasi Ekonomi Vol.1 No.2 Hal 64-76

Selim Ahmed and Md.Habibur Rahman. 2015) The Effects of Marketing Mix On Costumer Satisfaction: $A$ Literature Review From Islamic Perspectives Journal Vol.2 No.1 Hal.17-30

Setiawan Budi Utomo, 2003, Fiqih aktual: jawaban tuntas masalah kontemporer, Gema Insan Jakarta hal.134-135

Sugiyono, 2012, Metode Penelitian Kuantitatif, Kualitatif, Dan $R \& D$, Alfabeta, Bandung

Sugiyono, 2012. Metode Penelitian Pendidikan Pendekatan Kuantitatif, 
Kualitatif dan R\&D. Bandung :Alfabeta.

Sukotjo dan Radix 2010. Analisa Marketing Mix 7P (Product, Price, Prmotion, Place, Partisipant, Process, Physical eviden) terhadap keputusan pembelian produk klinik kecantikan teta disurabaya, Jurnal Mitra Ekonomi dan Manajemen Bisnis Vol.1 No.2 Hal 216-228

Sumarni, Murti dan John Soeprihanto. 2010. Pengantar Bisnis (Dasar Dasar
Ekonomi Perusahaan). Edisi ke 5. Yogyakarta:Liberty Yogyakarta.

Sumarwan Ujang M,Sc,2011, Prilaku konsumen Teori dan Penerapannya Dalam Pemasaran, Jakarta :PT Ghalia Indonesia.

Yusuf, A Muri. 2014. Metodelogi Penelitian Kuantitatif, Kualitatif dan Penelitian. Gabungan. Jakarta: Prenadamedia Group. 